\title{
A comparative study of supervised classification techniques for dynamics assessment of land use and land cover in the Brazilian Amazon
}

\author{
A Case Study on Settlement 26 de Março. \\ Flavia Pessoa Monteiro, Priscila Siqueira Aranha, Paulo André Ignácio Pontes, Jorge \\ Antonio Moraes de Souza, Nandamudi Lankalapalli Vijaykumar, Maurílio de Abreu \\ Monteiro and Carlos Renato Lisboa Francês.
}

\begin{abstract}
The Amazon is one of the most complex and diverse biomes in the world and their level of environmental preservation has global scope of impact. However, apart from the environmental aspects, the complexity of the region involves other different views such as: social, economic and cultural. Indeed, such views are inextricably linked, so that, for example, cultural aspects can affect the relationship between the land use and land cover and, in the case of Amazon, depending on the scale of these changes, there may be consequences planetary. Depending on the criticality involving the region, various government actions, organizations and social movements and the international community, has been trying to rationalize the land use and land cover, in order to create a sustainable relationship of exploitation of natural resources. An important government program is based on the creation of settlements, with their support, with regard to certain infrastructure financing, machinery, seeds and seedlings, technical assistance, among others. However, despite the work involved, the solution is extremely complex, given the correlation of factors to be assessed and combined in search of success and improvement of such programs. So on behalf of all complexity involved, is of paramount importance the use of technological tools to measure the degree of evolution of theland use and land cover in the regions that are part of the Amazon forest. One of the fundamental assessments is the observation of the evolution of land use change, because it is a temporally changing variable, with severe implications on the natural landscape and the environment as a whole.This study aims to evaluate the performance of computational techniques SVM, Neural Networks, Maximum Likelihood and Decision Tree to better classify the images of Landsat 5 satellite on the scene of the Brazilian Amazon. Data mining techniques are being used increasingly used for satellite image classification purposes, among various techniques there is the decision tree. This technique improved the classification accuracy and very efficient computational way, as the results were generated automatically and optimized time. The study area, concentrated in the settlement 26 de Março / Maraba, are facing serious problems in its reforestation. This settlement is only a reflection of occurring in the Amazon biome and its complex and diverse environmental system.
\end{abstract}

Keywords-Image Classification, LULC, LULCC, LANDSAT 5 satellite, 26th March Settlement, TerraClass, Decision Tree, Random Forest, SVM, CART, MPL.

\section{Introduction}

The Amazon is one of the most complex and diverse biomes in the world and their level of environmental preservation has global scope impact. Facing this problem, various government actions, from organizations and social movements, and from the international community, has been trying to rationalize the use and land cover, in order to create a sustainable relationship of exploitation of natural resources.

In Brazil, was created in 1970 a government agency called INCRA (National Institute for Colonization and Agrarian Reform) which its main task is to perform the national land planning focused on land reform. Agrarian Reform consists of a set of measures in order to promote a better distribution of land, establishing guidelines for environmental licensing of settlement projects, aimed at sustainable development [1]. Over the years, the settlement areas have become a major element of the countryside in the Legal Amazon, accounting for almost a third of the land used and almost $74 \%$ of farms, about 3,554 projects where around 752,000 families in 76.7 million hectares.

By measuring provisional $n{ }^{\circ} 2166-67$ of August 24, 2001 , were defined the area of permanent preservation and forest reserve to each settler class. The Permanent Preservation Areas (PPAs) were designed to protect the natural environment, which means they are not suitable areas for land-use change and should be covered with the original vegetation.

According to the study by Imazon [2], the deforestation levels in settlements in the Legal Amazon until 2010, reaches about $50 \%$ to $75 \%$ of the lots in 392 settlements, reaching about 40346 hectares of deforested areas. Thus, it is evident the need to create new measures in order to improve the control and supervision of those regions.

Currently, technological advances favored the emergence and improvement of various data collection techniques. Among the various methods of obtaining data and information about the geographic space, remote sensing has shown great potential in the acquisition of large volumes of geo-referenced data at different scales through images, been highly invested in projects aimed at mapping the use and coverage the earth.

To study the dynamics of land user and land cover in the Amazon is essential the use of remote sensing techniques, given the size of the region associated with difficult access. Although the mapping of land cover using satellite data to be widespread, even today there is still no consensus a standard methodology [3].

The visual interpretation of satellite images is a widely used method for satellite image classification of Landsat series. Although it is a precise technique it becomes quite expensive when applied to very large areas. The alternative 
to these manual methods is the use of computational intelligence techniques to image recognition standards [3].

This paper aims to propose a methodology for analyzing the land use and land cover in settlement projects in the Brazilian Amazon and evaluate the performance of computational techniques to perform supervised image classification, within the proposed methodology. To perform the evaluation, were selected the decision tree techniques, support vector machine (SVM), maximum likelihood and neural networks.

\section{Related Work}

Remote sensing plays a key role in monitoring the land use and land cover in the Amazon, because it offers historical and current information to a wider environment and difficult to access. Classification is a process of extracting information that covers a set of techniques, that can be mathematical or statistical, and the main purpose is to automate the categorization of all the pixels of an image within subjects or classes of land use and land cover.[4]

A methodology that takes advantage of supervised and non-supervised classifications is proposed in [17]. On the other hand, [16] and [15] compared Support Vector Machine-SVM, Artificial Neural Networks-ANN and Maximum Likelihood Classification-MLC to infer which could be the best technique to classify images. All the three showed to be equivalent with a $94 \%$ of precision to classify land coverage in coastal areas [16]. [15] showed that ANN had a better performance than SVM and MLC but requires a deeper understanding to clearly define in which situations ANN is in fact better as the authors expected that SVM would perform better. In [14], Classification and Regression Trees-CART, ANN and SVM were compared and showed that SVM could be more generalized than others when using small training samples. Precision obtained was between $70 \%$ and $80 \%$ for samples between 20 and 800 pixels. ANN produced around $67 \%$ to $76 \%$ of precision while CART $62 \%$ to $73 \%$. MLC was applied to study land use and coverage of Yamuna River bed in Delhi [14] and obtained a precision of around $77.1 \%$ and $88.6 \%$ with Kappa coefficient of 0.71 to 0.86 .

MLC and Decision Tree were employed [10] to classify an area in Victoria, Australia and results showed a precision of $74 \%$ to $78 \%$ with Kappa coefficient of 0.70 and 0.75 respectively. Decision Tree algorithm had a better performance. [11] analyzed territorial dynamics of land coverage in the State of Rondônia also recognized as deforested area. The authors employed supervised classification based on Bhattacharya algorithm associated to image segmentation by Spring software [Câmara et al., 1996]. The study mapped seven different classes of land use and coverage besides identifying changes occurred in the area.

A study on Tourist State Park in Alto Ribeira, São Paulo State investigated the performance of different classification methods to map land coverage [12]. Two methods - hybrid classification per pixel (ERDAS 9.1 software) and classification based on objects (eCognition version 5 software) - were employed. Object-based classification performed better with a Kappa coefficient of 0.8687 (hybrid classification obtained a Kappa coefficient of 0.2224). The expected quality was obtained due to domain specialist knowledge during the classification process. ANN was evaluated by [13] to classify images to analyze land use and coverage. It showed to be efficient, especially, when that input data were not normally distributed. For complex mapping applications, the authors recommend to employ supervised MLP (Multi Layer Perceptron) networks that could classify images with better precision. They also recommend non-supervised SOM (Self-Organizing Mapping) to analyze spectral features between and within the classes.

Soe W. Myint, Patricia Gober, Anthony Brazel, Susanne Grossman-Clarke e Qihao Weng conducted a study comparing a classification algorithm based on objects and the MLC. The classifier based on objects was given an overall accuracy of $90.40 \%$, while the MLC technique achieved $67.60 \%$ [6].

\section{Methodology}

Once the problem is established, a methodology has been defined to qualify the deforestation and then classify the satellite images by distributing each pixel in thematic classes. Maps from TerraClass project from 2008 to 2015 [18] were used.The main objective of TerraClass [18] is to qualify deforestation in Legal Amazon based on deforestation mapped and published by PRODES project [INPE, 2008] and by satellite images, mapping land use and coverage and also enabling to the evaluation of this dynamics. It consists of four main stages, executed manually and automatically. The first refers to data pre-processing based on acquiring satellite images. Then, GIS (Geographic Information System) is used to compose bands and geometric correction. Lastly, regio of interest is extracted. They are manually performed in sequence for all the obtained images. Once the first phase is over, images are stored in a repository so that they go through classification as shown in Figure 1. 
Proc. of the Intl. Conf. on Advances in Applied science and Environmental Technology - ASET 2015. Copyright (C) Institute of Research Engineers and Doctors, USA .All rights reserved.

ISBN: 978-1-63248-040-8 doi: 10.15224/ 978-1-63248-040-8-88

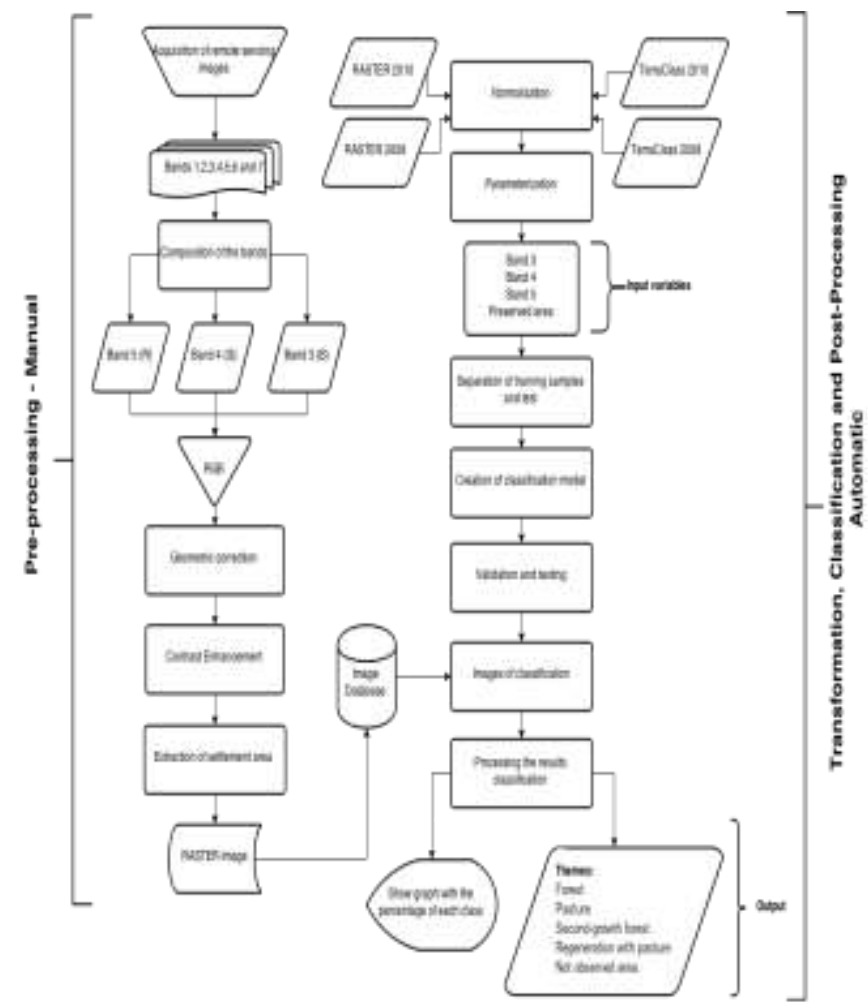

Figure 1. Model of the methodology

The next phases are automatically executed by an algorithm written in Python. It follows the steps from Figure 1 starting from executing the transformation phase to data normalization as well as definition of input variables to be used during the classification. Results from the classification go through a pre-processing and presented in tabular and graphic forms with the percentage values of each area by thematic class. Percentage figures of each area by its thematic class are also shown along with the classified image.

\section{A. Study Area and Data pre- processing}

The study area corresponds to PA 26 de Março, created on 19/December/2008. It used to belong to Cabeceiras farm located in Marabá, meso-region of the Southeast of Pará (Figure 2). Its area is $11,919.36$ ha with 6 clusters of houses and two headquarters besides 207 family lots [19].

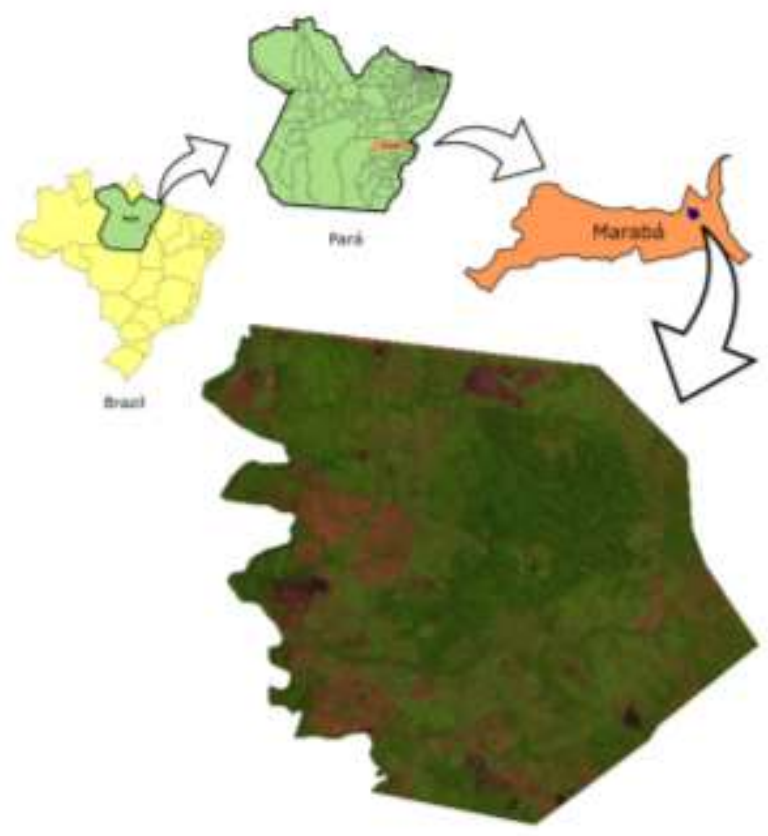

Figure 2. Study Area

In order to perform this study, LANDSAT 5 (Land Remote Sensing Satellite) satellite images, Thematic Mapper (TM). The TM sensor contains frequency bands with a resolution of 30 meters for tracks 1,2, 3 (visible range), 4, 5 and 7 (infrared bands), and with a resolution of 120 meters for track 6 (infrared range)

For remote sensing each band spectral has a specific application that differentiates it from the others. Knowledge of these applications is critical to defining the best combination of frequencies to represent the thematic classes that will be studied.

TABLE 1. STYLE AVAILABILITY OF SATELLITE TM SENSOR BANDS LANDSAT 5

\begin{tabular}{|c|c|c|}
\hline \multicolumn{3}{|c|}{ Satellite Landsat 5 - TM Sensor } \\
\hline Band & $\begin{array}{l}\text { Spectral Range } \\
(\mu \mathrm{m})\end{array}$ & Main applications \\
\hline 1 & $0.45-0.52$ & $\begin{array}{l}\text { Great penetration into cups with } \\
\text { water and sensitivity to plumes of } \\
\text { smoke coming from burnt or } \\
\text { business }\end{array}$ \\
\hline 2 & $0.52-0.60$ & $\begin{array}{l}\text { Great sensitivity to the presence of } \\
\text { sediments suspended and } \\
\text { Reflectance vegetation healthy }\end{array}$ \\
\hline 3 & $0.63-0.69$ & $\begin{array}{l}\text { Differentiation of } \\
\text { vegetables }\end{array}$ \\
\hline 4 & $0.76-0.90$ & $\begin{array}{l}\text { Sensitivity to cup roughness forests } \\
\text { and the morphology of the terrain }\end{array}$ \\
\hline 5 & $1.55-1.75$ & $\begin{array}{l}\text { Sensitivity to moisture content of } \\
\text { plants }\end{array}$ \\
\hline 6 & $10.4-12.5$ & $\begin{array}{l}\text { Sensitivity to the phenomena } \\
\text { relating to thermal contrasts }\end{array}$ \\
\hline 7 & $2.08-2.35$ & $\begin{array}{l}\text { Sensitivity to the terrain } \\
\text { morphology }\end{array}$ \\
\hline
\end{tabular}

After the geo-processing, a database was created adopting a 1:25.000 scale with geographic coordinates SIRGAS 2000. Images were obtained from Brazilian Institute for Space Research (INPE) (http://www.dgi.inpe.br/CDSR/).

The collected images were selected according to the percentage of cloud coverage not going beyond 5\% threshold. With this criterion, 12 images between 1986 and 2010 were selected also following an interval o 2 to 3 years. In order to minimize seasonal effects of the changes on the land use and coverage, the selected images were between the months of July and September.

The original images obtained haven't been through any type of treatment and present noise due to atmospheric 
influence and geometric distortions. So, it is imperative to adjust these images in order to avoid problems with quality and validity of extracted information. Once such inconsistencies are sorted out, multi-temporal datasets obtained can now be used in the normalization phase with much more reliability. So, the pre-processing is critical and influences on the quality/validity of the extracted information.

During the pre-processing, ArcGIS, version 10.0 was used. Geometric and radiometric corrections were applied to deal with the positioning and intensity of the pixel values that usually are frequent due to variation of altitude, velocity and atmospheric conditions in the sensors of the satellite [18]. With an objective of improving the quality of the image, contrast highlighting was applied to distinguish the elements of the image. Empirically, Minimum-Maximum was opted to manipulate the histograms

Spatial resolution had to be uniform in $30 \mathrm{~m}$. So, resampling based on closes neighbor was used fixing the error a 0.5 pixel that might generate discontinuity on the resampled image, but without changing the radiometric values of theoriginal image. The radiometric values refers to the sensing system's ability to detect variations in spectral radiance received. The radiance of each pixel goes through a digital encoding, obtaining a numerical value, expressed in bits, called Digital Number (DN). This value is easily translated into a visual intensity or a gray level is located in a finite interval $(0, K-1)$, where $\mathrm{K}$ is the number of possible values, called quantization levels[20].

To minimize the effects due to the combined use of different bands, the same numbers of the bands were used for the all the images. In order to compose the bands, 5, 4 and 3 bands were selected, as they were more representative to distinguish vegetation coverage and to map land use. ArcGIS software was employed to collect training samples and testing samples for the classification phase. TerraClass 2010 was the basis to select the samples. The ideawas to qualify deforestation, mapping the land use and coverage in the Legal Amazon from LANDSAT 5 TM satellite images divided into their respective orbit-points.

TerraClass maps all the Legal Amazon and it is expected that the classification may present some inconsistencies when the region of interest is very small as it is the case for Settlement 26 th March. So, to minimize such distortions, samples were extracted in polygon shapes of those regions whose correspondence between the original and classified images is true.

For the parameterization, input values and output thematic classes were defined. Output classes were forest, secondary vegetation, pasture, regeneration with pasture and non-observed area (clouds and forest regional fires) due to their significance for the region of interest. Input values were the gray levels of bands 3, 4 and 5, and the variable "preserved area", of binary type with 0 or 1 . To classify an image of the year $\mathrm{x}$, for example, all the pixels of classified image for the year $x-1$ are verified. If the pixel corresponds to forest, 1 is assigned to the variable, otherwise 0 . Its main objective is not to allow that deforested areas are classified as forest.

\section{B. Supervised Classification}

Monitoring and mapping of land use and land cover, various data mining techniques have been successfully used are in local scales, regional and global due to the high degree of detail obtained with these classification tools [21].

For the selection of techniques that will be evaluated in this study, we sought to supervised classification models that associate at least two of the following characteristics: accuracy, speed and simplicity. For this task were selected four techniques: decision tree, maximum likelihood, support vector machine and artificial neural networks.

The Decision Trees (DT) are simple representations of knowledge and an efficient way to build classifiers that predict classes based on the values of attributes of a data set In a decision tree, knowledge is tested and shown on each node that can lead the search to one node of his sons, top down [14]. The DT algorithms have advantages for the classification of land cover, including, therebetween, can be cited: ease of interpretation of the results, low processing time, the model's ability to work with data measured on different scales, the fact it does not require normal distribution of data and the ability to process the nonlinear relationships between the predictors and land cover classes [22].

The algorithms of DT were selected for evaluation: o CART (Classification and Regression Trees) e o Random Forest (RF). The CART algorithm proposed by [19], has a main advantage sought, that is the great ability to search relations between the data and the generation of results in simple decision trees and readability. The algorithms Random Forest is a combination of predictions of several trees in which each tree depends on the values of an independent vector, sampled randomly and with the same distribution for all trees in the forest. Forest is the name given to a series of decision trees [23].

The statistical technique of Maximum Likelihood (MLC) was used in this study, only for the purpose of comparing the accuracy of the method implemented by the tool GIS, compared to other algorithms studied. O MLC is a method of more common pixel $\mathrm{x}$ pixel based classification, which considers the weighing of the distances between means of digital levels of classes, using statistical parameters, therefore, a fairly large number of pixels is required for each training set.

The technique of Support Vector Machine - SVM is a machine learning technique, which seeks to minimize the error with respect to the training set, and the error with respect to the test set. Aims to achieve a balance between these errors, minimizing excess adjustments with respect to training samples (overfitting) and consequently increasing the capacity of generalization[24].

The technique of artificial neural networks (ANN) has been successfully applied in image processing and pattern recognition areas. A ANN using non-linear computing elements (called neurons) as networks organized in a manner analogous to the functioning of the human brain [25].

In order to obtain reliable results for comparison of different techniques, we used the method of pixel-by-pixel classification. Another reason for choosing this method with respect to the size of the study area. Because it is a 
Proc. of the Intl. Conf. on Advances in Applied science and Environmental Technology - ASET 2015. Copyright (C) Institute of Research Engineers and Doctors, USA .All rights reserved.

ISBN: 978-1-63248-040-8 doi: 10.15224/ 978-1-63248-040-8-88

substantially small area in relation to the Amazon region, makes it much more sensitive to the classification error because each pixel rated mistakenly direct impact on the end result.

\section{Precision Evaluation}

It is important to evaluate the quality of the classification results as it is concerned with extracting intended patterns from the input data. Here, confusion matrix and Kappa coefficient were used to express the precision of the classification techniques. Confusion matrix enables understanding the behavior of the classifier, reacting to effects of wrong prediction. Rows represent expected values and columns real ones. As per Kappa coefficient, it evaluates how good is the model. It is a discrete multivariate technique that determines the level of the precision varying between 0 and 1 . Closer to 1 , better is the classification result.

TABLE 2. COMPARISON OF ACCURACY AND KAPPA INDEX

\begin{tabular}{|c|c|c|}
\hline Technique & Accuracy & Kappa Index \\
\hline DT - Random Forest & $98 \%$ & 0.975 \\
\hline DT - CART & $97.7 \%$ & 0.964 \\
\hline SVM & $97.7 \%$ & 0.968 \\
\hline ANN & $95 \%$ & 0.968 \\
\hline MLC & $82.75 \%$ & 0.78 \\
\hline
\end{tabular}

The test samples used for classification of the use and land cover, obtained a better result for Randon Forest technique with a success rate equal to $98 \%$, with a kappa index of 0.975 , featuring an excellent model created. The models created by the SVM and CART techniques, as well as the prior art, also obtained a model that represents an excellent level of agreement behind only by $0.3 \%$ error rate.

The ANN technique through its best configuration (four neurons in the input layer, seven neurons in the hidden layer and output layer for five) achieved an excellent model with an accuracy rate of $95 \%$ and kappa index 0.968 .

The worst evaluated technique was MLC, for the reason that it require a large volume of basic training. Beyond the technical reason have got a result $15,25 \%$ worse than the best available technique, it will not be used to map the dynamics of the use and coverage of the settlement 26 de Março, because you can not add the variable "preserved area" to create the model in ArcGIS software.

TABLE 3. CONFUSION MATRIX (\%) OF LAND USE AND LAND COVER CLASSIFICATION.

\begin{tabular}{|c|c|c|c|c|c|}
\hline \multirow{2}{*}{ Class(\%) } & \multicolumn{5}{|c|}{ Classification techniques } \\
\cline { 2 - 6 } & RF & CART & SVM & ANN & MLC \\
\hline Forest & 99,68 & 98,75 & 99,67 & 99,83 & 83.53 \\
\hline $\begin{array}{c}\text { Second-growth } \\
\text { forest }\end{array}$ & 98,05 & 97,76 & 98,85 & 85,32 & 76.67 \\
\hline
\end{tabular}

\begin{tabular}{|c|c|c|c|c|c|}
\cline { 5 - 6 } & 97,82 & 97,80 & 96,03 & 96,80 & 66.92 \\
\hline $\begin{array}{c}\text { Regeneration } \\
\text { with pasture }\end{array}$ & 98,68 & 98,33 & 98,68 & 97,25 & 91.30 \\
\hline $\begin{array}{c}\text { Not observed } \\
\text { area }\end{array}$ & 95,20 & 94,66 & 94,40 & 86,97 & 92.06 \\
\hline
\end{tabular}

The results presented in Table 3 indicate that the Random Forest technique achieved higher accuracy in classification of all classes, except in the Forest, which was less than $0.15 \%$ over the classification performed by ANN technique. Comparing the results obtained by MLC with other techniques evaluated, we can identify in the case of unobserved area class, there were opposite behavior. In technical MLC the best results was the identification of the class, differing from other techniques that lost this classification accuracy.

In the next topic will be presented the results of the classification of the models created by the RF, CART, SVM and ANN techniques, to define the best technique suitable for the mapping of the dynamic's use and cover of the settlement 26 de março.

\section{Results}

For this study, five classes were defined: forest, pasture, regeneration with pasture, second-growth vegetation and non-observed area. After employing classification techniques, it is clear that there is fragility in classifying small areas from TerraClass. It is important to point out that TerraClass is an excellent tool to deal with Legal Amazon with continental dimensions.

Based on the results and metrics obtained with the classification techniques evaluated for this work, we can point the best technique for the classification of images in the time series selected for the study of the dynamic's land use and land cover, on the nesting region 26 March. the best technique was evaluated the decision tree with the Random Forest algorithm, with a hit rate of $98 \%$ and Kappa index of 0.975 .

Analyzing the graphic in Figure 3, we can say that with the technical Random Forest, the proportion of forest area fell by $9 \%$ over the classification performed by TerraClass project of 2010, which means about 1072.74 ha without the original cover. It may also be noted that the classification technique used in this article is more accurate to identify regions of the area observed class, an increase of $6.19 \%$ compared to TerraClass. Figure 3 also shows a large discrepancy between the RNA technique compared to other techniques, especially in the areas of classification Forest and Secondary Vegetation. This was the only classifier with a larger forest area as compared with the TerraClass project. The CART and SVM techniques, had the same behavior that the model Random Forest, but with less precision.

Were classified the images of the historical series of the settlement studied using all the techniques evaluated, except the maximum likelihood technique, because it was not possible a fair just comparison, for the same reason do not use the input variable proposal "preserved area". 


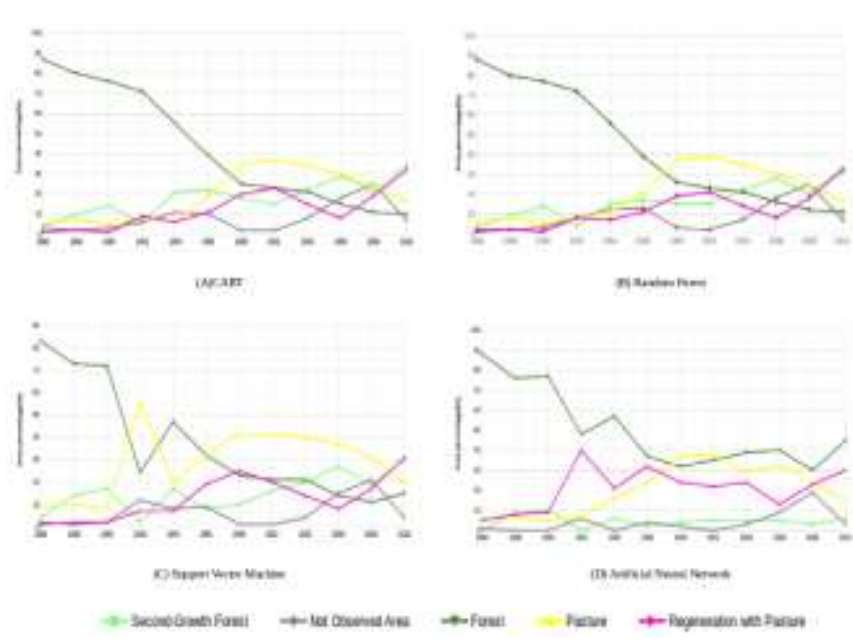

Figure 3. Classification techniques of the dynamics of land use and land cover

Figure 4 presents the results of classification techniques of the dynamics of land use and land cover. From the graphs it is possible to identify that with the techniques of SVM and RNA, even when using the variable "preserved area", still suffer from irregular variation of the dynamics of forest area. Between 1990 to 1992, he hears a sharp drop in the area of this class and the correct trend is that this percentage will continue to decline over the years, which did not occur, since between the years 1992 and 1994 the percentage of the area of this same class grows back. For the SVM technique this variation was more significant, with a fall of $48 \%$ and an increase of $23 \%$ compared to the variation of RNA, which obtained a decrease of $29 \%$ and $9 \%$ increase. You can also see that in the case of SVM, this decrease was a result of increased pasture class area, different from RNA, which had increased class regeneration with Pasto.

Based on the classification from DT, one can perform que vegetation coverage of 26 th March Settlement Suffered the high degradation, giving place to large areas of pasture. Such dynamics may be Explained from the struggle for land ownership between the MST-Movement of Workers without Land and owners of Headwaters farm que lead to cutting down a great part of the native forest Thus trying to show que the lad was productive to avoid expropriation by government in the land reform program. In 2008, When the settlement was created, Those Were que que Were settled areas received highly anthropic. But, deforestation remains, at a slower pace, of course. This Occurs due to lack of resources of the families settled que are unable to maintain the clean pastures leading to, time to team, deforesting new areas. The abandoned pastures give place to regeneration with pasture and at a later stage to secondary vegetation as can be Observed in Figure 4, item B.

\section{v. Conclusion}

The study indicates that the use of decision tree classification technique, either with the Randon Forest algorithm or with CART, obtained a higher overall accuracy between 97 and 98\%, kappa coefficient between 0.96 and 0.97 , plus a lower processing cost as compared with the other studied techniques. Based on the results obtained by the decision tree technique, we observed that the landscape of the settlement March 26 is dominated by pastures and the forest areas decreased significantly due to this practice. This study also showed a gain in relation to the work of [10] obtained an accuracy of $78 \%$ with the use of decision tree technique.

The multi-temporal analysis of land use and land cover is key to understanding the dynamics of occupation of the settlement projects, particularly in the Brazilian Amazon, generating subsidies for more effective public policies to control deforestation and the establishment of good practice in land management. This analysis is linked strongly to the quality of the satellite image classification. Because of this, the establishment of a methodology to guide the study from obtaining the images until their classification, and in which all cases after the pre-processing are performed automatically, without the need for model training every time an image suffer the classification, which optimizes time and computational effort, as presented here, is of great value.

In addition, the presentation of a comparative study of the classification techniques most commonly used for the analysis of land use and land cover, applied to the case of settlement projects in the Amazon region, emerges as an important contribution to the understanding of the movements that occur these areas.

As future work we intend to use computational intelligence techniques to integrate to analysis of the land use and land cover, socio-economic information of the settlements, and meteorological variables and soil quality. Information collected by wireless sensor networks and photographs taken from drones, will also be incorporated. Thus, the study will be much more complete.

\section{References}

[1] Incra. 2003. "Plano Nacional de Reforma Agrária, Projeto de Assentamento Floresta"l. Available in: http://www.incra.gov.br/Consulta\%20Publica.pdf.

[2] Imazon. "Desmatamento nos Assentamentos de Reforma Agrária na Amazônia”. 2013. Disponível em: http://imazon.org.br/.

[3] V. C. Honório, and N. E. M. Leão, "Mapeamento do uso e cobertura da terra a partir dasegmentação e classificação de imagens - fração solo, sombra e vegetação derivadas do modelo linear de mistura aplicado a dados do sensor TM/Landsat5, naregião do reservatório de Tucuruí - PA.", Acta Amazônica, INPE 2002. [Publication of Instituto Nacional de Pesquisas da Amazônia]

[4] Z. Liang, S. Jinping, S. Huiyond, Y. Gang, and J. Yi, "Large area Land Cover Classification with LANDSAT ETM+ Images based on Decision Tree.", 2012 [International Archives of the Photogrammetry, Remote Sensing and Spatial Information Sciences, Volume XXXIX-B7]

[5] I. Meliadis, and M. Miltiadis, "Multi-temporal Landsat image classification and change analysis of landcover/use in the Prefecture of Thessaloiniki, Greece", 2011. [Department of Forest Management and Remote Sensing, School of Forestry and Natural Environment, Aristotele University of Thessaloniki, Greece]

[6] S. Yang and L. S., Ross, "Comparison of support vector machine, neural network, and CART algorithms for the landcover classification using limited training data points", 2012 [ISPRS Journal of Photogrammetry and Remote Sensing 70]

[7] M.W. Soe, G.Patricia, B. Anthony, C.G. Susanne, and W. Qíhao, "Per-pixel vs. object-based classifi cation of urban land cover extraction using high spatial resolution imagery. ", 2011 [Remote Sensing of Environment 115]

[8] Y. Hui, W.V. Cynthia, K. Siamak, "An Automated Artificial Neural Network System for Land Use/Land Cover Classification 
Proc. of the Intl. Conf. on Advances in Applied science and Environmental Technology - ASET 2015.

Copyright (C) Institute of Research Engineers and Doctors, USA .All rights reserved.

ISBN: 978-1-63248-040-8 doi: 10.15224/ 978-1-63248-040-8-88

from Landsat TM Imagery." Remote Sens. 2009, 1, 243-265; doi:10.3390/rs1030243.

[9] T. Rittl, M. Cooper, R.J. Heck, and M.V.R. Ballester, "ObjectBased Method Outperforms Per-Pixel Method for Land Cover Classification in a Protected Area of the BrazilianAtlantic Rainforest Region.", 2013 [Published by Elsevier B.V. and Science Press]

[10] Z. Liang, S. Jinping, S. Huiyong S, Y. Gang and J. Yi. Large area Land Cover Classification with LANDSAT ETM+ Images based on Decision Tree.

[11] Z. Liang, S. Jinping, S. Huiyond, Y. Gang, and J. Yi, "Large area Land Cover Classification with LANDSAT ETM+ Images based on Decision Tree.", 2012 [International Archives of the Photogrammetry, Remote Sensing and Spatial Information Sciences, Volume XXXIX-B7]

[12] T. Rittl, M. Cooper, R. J. Heck and M. V. R. Ballester. "ObjectBased Method Outperforms Per-Pixel Method for Land Cover Classification in a Protected Area of the Brazilian Atlantic Rainforest Region".

[13] Y. Huin, F. Cynthia, D. W. Van, K. Siamak. "An Automated Artificial Neural Network System for Land Use/Land Cover Classification from Landsat TM Imagery". Remote Sens. 2009, 1, 243-265; doi:10.3390/rs1030243.

[14] S. Yang and R. S. Lunetta. "Comparison of support vector machine, neural network, and CART algorithms for the landcover classification using limited training data points". ISPRS Journal of Photogrammetry and Remote Sensing.

[15] K. Srivastava, H. Dawei, M. A. Rico-Ramirez, B. Michaela, T. Islam. "Selection of classification techniques for land use/land cover change investigation". Advances in Space Research (a COSPAR publication).

[16] W. B. Szuster, Q. Chen, B. Michael. "A comparison of classification techniques to support land cover and land use analysis in tropical coastal zones". Applied Geography.

[17] H. Saadat, J. Adamowski, R. Bonnell, F. Sharifi, M. Namdar, S. Ale- Ebrahim. Land use and land cover classification over a large area in Iran based on single date analyses of satellite imagery. ISPRS Journal of Photogrammetry and Remote Sensing.

[18] CRA/INPE. Projeto TerraClass. 2010. Acesso: Junho 2014.

[19] H. Thomas. "Agricultura Familiar e Desenvolvimento Rural Sustentável na Amazônia". Novos Cadernos. NAEA v. 8, n. 1 p. 019-071 jun. 2005.

[20] R. A. Schowengerdt. "Techniques for Image Processing and Classification in Remote Sensing". University of Arizona. 1983. $249 \mathrm{p}$.

[21] S. E. Sesnie, P. E. Gessler, B. Finegan, S. Thessler . "Integrating Landsat TM and SRTM-DEM derived variables with decision trees for habitat classification and change detection in complex neotropical environments. Remote Sensing of Environment".v. 112, p. 2145-2159, 2008.

[22] M. A Friedl and C. E. Brodley. "Decision tree classification of land cover from remotely sensed data. Remote Sensing of Environment".

[23] L. Breiman, L, J. H. Friedman and R. A. Olshen and C. J. Stone. "Classification and regression trees". Belmont, CA:Wadsworth International, 1984.358p.

[24] V. N. Vapnik. "The Nature of Statistical Learning Theory". USA: Springer, $2 \mathrm{Nd}$ ed.,1999.

[25] R. C. Gonzales and R. E. "Woods Processamento de Imagens Digitais". São Paulo: Edgard Blücher Ltda., 2000.527 p.

About Author (s):

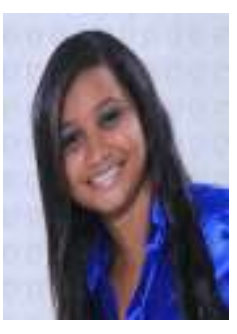

Master student in Electrical Engineering in the field of Applied Computing at the Federal University of Pará. Graduated in Computer Engineering from the Community College of the Amazon (IESAM). Has experience in applications development for Digital TV, Web systems development using Java and PHP and the study of network simulations using the Network Simulator 3 .

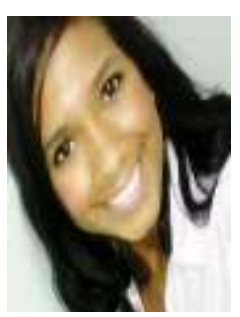

Studying currently Masters sandwich at the National Institute for Space Research - INPE in São José dos Campos. Master's Degree in

Electrical Engineering - Applied Computing at the Federal University of Pará - UFPA (2013). Has experience in wireless sensor networks and embedded systems.

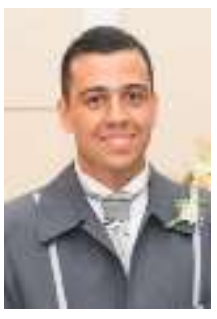

Effective Teacher of the Federal Institute of Education, Science and Technological Para IFPA. Have Graduation in Technology in Data Processing by the Pará State University Center -

CESUPA (2003). Specialist in Application

Development for internet by the Federal

University of Para - UFPA (2004). Master in Electrical Engineering in computing applied by UFPA (2013). PhD in Electrical Engineering in computing applied by UFPA (2014)

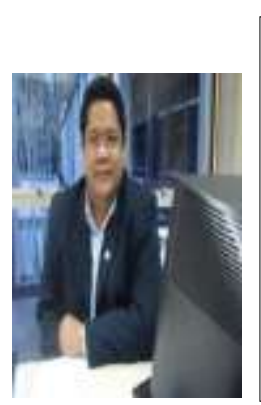

Graduated in Data Processing Technology in the University of the Amazon (1996) and master's degree in Computer Science and Computational Mathematics from the University of São Paulo (2000). He is currently a doctoral student at the Federal University of Pará and assistant professor in the Amazon Federal Rural University. He has experience in computer science, with emphasis on data communication technologies, mainly in the following themes: performance evaluation and wireless sensor networks.

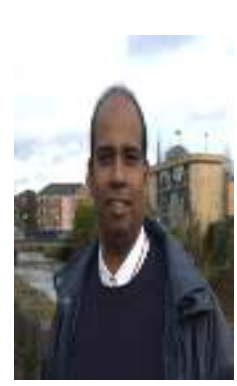

$\mathrm{PhD}$ in Electronic Engineering and Computing (area: Computer) from the Technological Institute of Aeronautics (1999). Participated in the Postdoctoral program at University College Cork (UCC) in Coastal and Marine Resrouces Centre (CMRC), Cork, Ireland in the area of computer modeling coastal environment.He has experience

in computer science, with emphasis on Performance Evaluation, Software Testing with Formal Specification, Time Series Analysis and Computational Modeling of coastal environment.

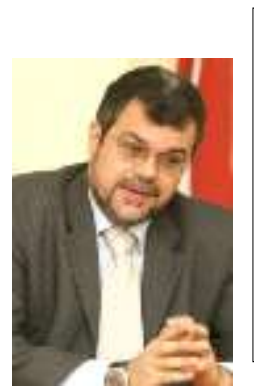

Graduated in History (1991), with a Masters in Development Planning (1996), both from the Federal University of Pará (UFPA). She holds a doctorate in Sustainable Development in the Humid Tropics (2001), also by UFPA, institution where he is a professor since 2002. He has conducted research in which addresses economic, social and spatial implications of the conversion of natural resources into commodities, with special attention to the Amazon Brazil's east.

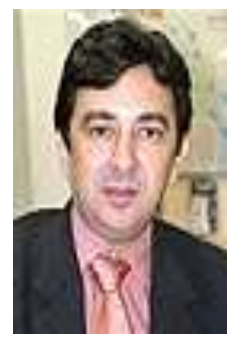

Graduated in Bachelor of Computer Science from the Federal University of Pará (1995), master's degree in Computer Science and Computational Mathematics from the University of São Paulo (1998) and a PhD in Computer Science and Computational Mathematics from the University of São Paulo (2001). Has experience in computer science, with emphasis on performance evaluation, acting on the following topics: Digital TV, Access Technologies, performance Markov models and simulation, correlation techniques (Bayesian networks) and optimization. 